\title{
Time to computerized tomography scan, age and mortality in acute stroke
}

Short title: Time to CT, age and mortality in acute stroke

Phyo Kyaw Myint ${ }^{1}$; MD; Andrew C Kidd ${ }^{2}$; MBChB; Chun Shing Kwok ${ }^{1,3}$; MBBS; Stanley D Musgrave $^{4}$; MD; Oliver Redmayne ${ }^{6}$; BSc; Anthony K Metcalf ${ }^{7}$ MBChB; Joseph Ngeh ${ }^{8}$; MD; Anne Nicolson ${ }^{9}$; MBBS; Peter Owusu-Agyei ${ }^{10}$; MBChB; Raj Shekhar ${ }^{11}$; FRCP; Kevin Walsh $^{12}$; MD; Diana J Day ${ }^{13}$; MSc; Elizabeth A Warburton ${ }^{13}$; PhD; Max O Bachmann ${ }^{4}$; PhD; John F Potter, ${ }^{4,7}$ DM; On behalf of the Anglia Stroke Clinical Network Evaluation Study (ASCNES) Group.

ASCNES Group Members: Max O Bachmann, Garry R Barton, Fiona Cummings, Genevieve Dalton, Diana J Day, Abraham George, Rachel Hale, Andrew C Kidd, Chun Shing Kwok, Anthony K Metcalf, Stanley D Musgrave, Phyo Kyaw Myint, Joseph Ngeh, Anne Nicholson, Peter Owusu-Agyei, John F Potter, Gill M Price, Raj Shekhar, Kevin Walsh, Elizabeth A Warburton.

\section{Current affiliations:}

${ }^{1}$ AGEING, Epidemiology Group, School of Medicine \& Dentistry, Academic Centre for Applied Clinical \& Translational Research into Ageing (ACTRA), University of Aberdeen, Aberdeen, Scotland, UK

${ }^{2}$ Gartnavel General Hospital, Glasgow, Scotland, UK

${ }^{3}$ Keele Cardiovascular Research Group, Keele University, Stoke-on-Trent, UK

${ }^{4}$ Norwich Medical School, Norwich, UK

${ }^{6}$ James Paget University Hospital, Lowestoft, UK

${ }^{7}$ Stroke Research Group, Norfolk and Norwich University Hospital, Norwich, Colney Lane, NR4 7UY, Norfolk

${ }^{8}$ Ipswich Hospital, Ipswich, UK

${ }^{9}$ West Suffolk Hospital, Bury St Edmund, UK

${ }^{10}$ Peterborough City Hospital, Peterborough, UK

${ }^{11}$ Queen Elizabeth Hospital, King's Lynn, UK

${ }^{12}$ Hinchingbrooke Hospital, Huntingdon, UK

${ }^{13}$ Addenbrooke's University Hospital, Cambridge, UK

$\neq$ This author currently base in Colchester Hospital, Colchester, UK

\section{Correspondence to:}

Professor Phyo Kyaw Myint

Epidemiology Group

Institute of Applied Health Sciences

University of Aberdeen, Foresterhill

AB25 2ZD, Aberdeen, UK

Telephone: +44 (0) 1224437841

Fax:+44 (0) 1603437911

Mail to: phyo.myint@abdn.ac.uk

Word count: 2,489 


\section{Abstract}

Background: Time to computerized tomography (CT) is important to institute appropriate and timely hyper-acute management in stroke. We aimed to evaluate mortality outcomes in relation to age and time to CT scan.

Methods: We used routinely collected data in eight National Health Service Trusts in East of England between September 2008 and April 2011. Stroke cases were prospectively identified and confirmed. Odds ratios for unadjusted and adjusted models for age categories $(<65,65-$ $74,75-84$ and $\geq 85$ years) as well as time to CT categories ( $<90$ minutes, $\geq 90$ to $<180$ minutes, $\geq 180$ minutes to 24 hours and $>24$ hours $)$ and the in-hospital and early( $<7$ days) mortality outcomes were calculated.

Results: Of 7,693 patients (mean age 76.1 years, 50\% male) included, 1,151(16\%) died as inpatient and 336(4\%) died within seven days. Older patients and those admitted from care home had a significantly longer time from admission until CT $(\mathrm{p}<0.001)$. Patients who had earlier CT scans were admitted to stroke units more frequently $(\mathrm{p}<0.001)$ but had higher inpatient $(\mathrm{p}<0.001)$ and seven-day mortality $(\mathrm{p}<0.001)$. Whilst older age was associated with increased odds of mortality outcomes, longer time to CT was associated with significantly reduced within 7 day mortality(corresponding ORs for above time periods were 1.00, 0.61(0.39-0.95), 0.39(0.24-0.64) and 0.16(0.08-0.33) and in-hospital mortality(ORs 1.00, $0.86(0.64-1.15), 0.57(0.42-0.78)$ and $0.71(0.52-0.98))$.

Conclusions: Older age was associated with a significantly longer time to CT. However, using CT scan time as a benchmarking tool in stroke may have inherent limitations and it does not appear to be a suitable quality marker.

Keywords: Stroke; Age; Computerized tomography; Outcome; Mortality 


\section{List of abbreviations}

$\begin{array}{ll}\text { AS\&HCN } & \text { Anglia Stroke \& Heart Clinical Network } \\ \text { ASCNES } & \text { Anglia Stroke Clinical Network Evaluation Study } \\ \text { CT } & \text { Computerised tomography } \\ \text { LACS } & \text { Lacunar stroke } \\ \text { mRS } & \text { Modified Rankin Score } \\ \text { NHS } & \text { National Health Service } \\ \text { NIHR } & \text { National Institute of Heart Research } \\ \text { NIHSS } & \text { National Institute of Health Stroke Score } \\ \text { OCSP } & \text { Oxfordshire Community Stroke Project } \\ \text { PACS } & \text { Partial anterior circulation stroke } \\ \text { POCS } & \text { Posterior circulation stroke } \\ \text { SHA } & \text { Strategic Health Authority } \\ \text { TACS } & \text { Total anterior circulation stroke } \\ \text { TIA } & \text { Transient ischemic attack } \\ \text { tPA } & \text { Tissue plasminogen activator } \\ \text { UK } & \text { United Kingdom } \\ \text { USA } & \text { United States of America }\end{array}$




\section{Introduction}

Treatment of acute stroke is aimed at salvaging potentially viable brain. Intravenous tissue plasminogen activator (tPA) is recommended if appropriate ${ }^{1}$ as it is associated with reduced infarct size and better functional outcomes if this is achieved rapidly. ${ }^{2}$ The delivery of therapy within recommended timeframe relies on rapid computerized tomography (CT) imaging to exclude hemorrhage, demonstration of which is also important as this may identify such patients for appropriate management. ${ }^{2}$ Hence, delays in CT scanning in acute stroke may have adverse impact on the patient.

While age is a major determinant of mortality outcome in any acute illness, it may also be an important determinant of the stroke care they receive in acute settings, with suboptimal compliance with many evidence-based processes of care for older stroke patients compared to younger patients, including receiving CT scans. ${ }^{3}$ Discrimination against older people and problems with overt and covert rationing of health care against older people has been previously highlighted. ${ }^{4}$ Not surprisingly, ageism against older patients has been the topic of much debate in various aspects including stroke management.

We have previously shown that increase in CT scan rate in older age was associated with a lower inpatient case-fatality rate, reduced length of acute hospital stay and more favourable discharge destination for older people with stroke compared with their younger counterparts. ${ }^{5}$ However, the study almost pre-dated the introduction of thrombolysis for ischemic stroke in the UK. Whether time to CT imaging is associated with a better outcome in stroke in the context of age in a consecutive stroke patient population has not been examined.

There is a need for further research aimed at developing an understanding of why agerelated differences exist in stroke management, particularly whether age differences in CT scan times exists and if so what were the impacts on acute mortality outcome. We aimed to 
better understand the complex relationships between age of the patient, time to CT (decision based on perceived clinical needs and service factors) and the acute stroke outcomes. We therefore investigated whether age is a determinant of the time period from arrival to hospital to CT scan and also examined the effect of age and time to CT scan on in-patient and early (within 7- day) mortality in acute stroke controlling for potential confounders.

\section{Materials and methods}

The Anglia Stroke \& Heart Clinical Network (AS\&HCN) was established by the East of England Strategic Health Authority (SHA) to support the development of stroke services in three counties in the East of England from which participants in Anglia Stroke Clinical Network Evaluation Study (ASCNES) was drawn. ${ }^{6}$ The ASCNES was funded by the NIHR Research for Patient Benefit Programme (PB-PG-1208-18240) and obtained ethical approval from the Norfolk Research Ethics Committee. The AS\&HCN was funded by the NHS Improvement Programme through the East of England SHA. AS\&HCN data were linked to ASCNES as part of collaboration agreement as per requirement for ASCNES anonymized data sharing.

Patients recorded in the AS\&HCN registry were those admitted between September 2008 and April 2011 to eight acute NHS Trusts in the East of England region with the catchment population of approximately 2.5 million. All patients included in the study were confirmed stroke cases (either ischemic or hemorrhagic stroke). Transient ischemic attacks and other vascular causes of neurological deficits presenting with stroke symptoms (e.g. (TIA) subdural hematoma, subarachnoid hemorrhage) were excluded from this study. AS\&HCN data collection was aimed at gathering process of care data of stroke services in relation to National targets and guidance from the Royal College of Physicians. ${ }^{7}$ 
The variables used in the current study were participants' age, sex, pre-stroke residence status (categorical - home, care home, other (e.g. rehabilitation facilities, sheltered accommodation)), pre-stroke modified Rankin (prestroke mRS), date of admission, time of admission, date of CT scan, time of CT scan, admission to stroke unit, presence of atrial fibrillation, type of stroke (ischemic or hemorrhagic), Oxfordshire Community Stroke Project (OCSP) classification (lacunar stroke (LACS), partial anterior circulation stroke (PACS), total anterior circulation stroke (TACS) and posterior circulation stroke (POCS)), ${ }^{8}$ systolic blood pressure, intravenous thrombolysis status, in-patient mortality and discharge destination. Those with diagnosis of TIA, missing time to CT scan and missing discharge destination were excluded $(\mathrm{n}=1,063)$ (see Supplementary Figure 1).

Statistical analyses were performed using Stata software, version 12.1 MP (Stata Corporation, Texas, USA). Medians, percentages, odds ratios (OR) and their $95 \%$ confidence intervals (CI) are reported as appropriate. The characteristics of patients and outcomes defined as in-patient death and in-patient death within 7 days according to time to CT scan were presented descriptively. Time to CT scan was calculated by subtracting time of CT scan by time of arrival to hospital. The time to CT categories were defined as $<90$ minutes, $90-180$ minutes, $>180$ minutes to 24 hours and $>24$ hours based on nearest quartile cut off points.

The odds ratios $(95 \% \mathrm{CI}$ ) for unadjusted and adjusted models for age categories and the study outcomes, in-patient mortality and within 7-day mortality, were also calculated. Adjusted model 1 adjusted for age and time taken to have CT after admission and model 2 additionally adjusted for sex, pre-stroke mRS, stroke type and OCSP classification. Age categories were defined as less than 65 years, 65 years to 74 years, 75 years to 84 years and $\geq 85$ years. The reference category for all outcomes was the bottom category $(<65$ years and CT time $<90$ minutes). A 3D plot of adjusted odds ratios of the 4 age categories and 4 times to CT categories was also constructed to better understand the complex relationships between 
CT time (decision to CT early or late) vs. age vs. outcome using less than 65 years old with CT less than 90 minutes as the reference category for the both outcomes examined. 


\section{Results}

Table 1 provides the sample characteristics and study outcomes according to the time to CT scan. Older patients were associated with a significantly longer time from admission until CT $(\mathrm{P}<0.001)$ and had more atrial fibrillation $(\mathrm{P}<0.03)$. Patients from care homes had a longer wait from admission until CT $(\mathrm{P}<0.001)$. Significantly higher proportion of patients who had CT scans within 90 minutes of admission were thrombolyzed compared to those with a longer time from admission until CT $(\mathrm{P}<0.001)$. Patients who had total anterior circulation strokes (TACS) did not get CT as urgently as those with posterior circulation strokes $(\mathrm{POCS})(\mathrm{P}<0.001)$. Patients who had earlier CT scans were also admitted to stroke units more frequently than those with a longer time from admission until $\mathrm{CT}(\mathrm{P}<0.001)$ but had higher in-patient and seven-day mortality ( $\mathrm{P}$ for both outcomes $<0.001$ ).

Table 2 shows the odds ratio and corresponding 95\% CI for inpatient and seven-day mortality according to age groups and then according to time to CT scan categories. After adjusting for age and time to CT scan (model 1), patients who were older had greater the odds of dying as an inpatient than younger patients. However those patients who had CT scans after 24 hours had lower odds of dying (OR $0.41(0.34-0.49))$ as an inpatient compared to those who had CT scans within 90 minutes (OR 1.00), but greater odds of dying as an inpatient compared with patients who had a CT scan between 8 and 24 hours (OR 0.36 (0.300.43)). Similar findings were observed in model 2 after adjusting for age, time to CT, sex, pre-stroke mRS, stroke type and OCSP classification.

After adjusting for age and time to CT scan (model 1), older patients also had greater odds of dying within seven days compared with younger patients. Those patients who had CT scans after 24 hours had lower odds of dying (OR 0.11 0.07-0.18)) within seven days compared to those who had CT scans within 90 minutes (reference category). After adjusting for age, time to CT, sex, pre-stroke mRS, stroke type and OCSP classification (model 2), 
those who had CT scans between 8 and 24 hours had lower odds of dying (OR 0.39 (0.240.64) within seven days compared to patients who had CT scans within 90 minutes (reference category), but greater odds of dying within seven days compared with patients who had CT scans after 24 hours (OR $0.16(0.08-0.33))$.

Figure 1 shows the 3D plot of the adjusted odds ratios of age group versus time to CT group for both in-patient mortality (Figure 1A) and seven-day mortality (Figure 1B).

\section{Discussion}

In this study we found that older age was associated with a significantly longer time to receiving brain $\mathrm{CT}$ imaging and also associated with increased stroke mortality after admission with an acute stroke compared to younger age. Additionally we found that patients admitted from care homes had a longer wait from admission until CT and patients who had total anterior circulation strokes did not get CT imaging as urgently as those with posterior circulation strokes. We also found that patients who had earlier CT scans received IV thrombolysis more often compared to those with a longer time from admission until CT. Moreover we found that patients who had earlier CT scans were admitted to stroke units more frequently than those with a longer time from admission until CT but had higher inpatient and seven-day mortality. This study adds to our previous work by evaluating the impact of CT scan times on in-patient mortality thus provides some insight into the agerelated differences in stroke management and outcome in the context of thrombolysis treatment in the UK setting.

Decision to perform an early CT scan appears to be driven by age and frailty indicator depicted by place of residence as well as the severity of stroke and also by potential for intravenous thrombolysis. Therefore those with very mild or most severe forms of strokes who were not suitable to be thrombolyzed had CT scans much later. However, irrespective of 
this, we have shown that a disproportionately high number of older people wait longer for a CT scan compared to their younger counterparts and this relationship appears to be linear. This was also true for patients arriving from care homes. This is in keeping with a recent systematic review which examined the published literature on whether older acute stroke patients received the same quality of care as younger patients, as measured by compliance with evidence-based process indicators. ${ }^{3}$ The authors of this review concluded that patients' age may be an important determinant of the stroke care they receive in acute settings, including receiving CT scans, and that there was sub-optimal compliance with many evidence-based processes of care for older stroke patients compared to younger patients. ${ }^{3}$

Previous studies which have examined the rates of CT scans and investigations in stroke management report similar findings. In a multi-centre European study of 4,499 patients with first-time stroke evaluated with regard to functional outcome patients aged $\geq 80$ years were compared with the younger age groups and brain imaging and other diagnostic tests were significantly less used in the older patients. ${ }^{9}$ Moreover a further study investigating variations in the use of diagnostic procedures across multiple European hospitals in first-time stroke patients also found that patients with increasing age were less likely to receive the diagnostic standard. ${ }^{10}$ This was also echoed in studies of patients with first-time strokes. ${ }^{11,12}$ The high mortality odds observed in older patients may be attenuated if they had similar timing for $\mathrm{CT}$ as their younger counterparts.

We found that patients who had earlier CT scans were admitted to stroke units more frequently than those waiting longer but had higher inpatient and seven-day mortality rates. The latter finding differs from a study examining three month mortality and functional outcome of European patients admitted to hospital with first time strokes. ${ }^{13}$ The authors in this study conclude that CT scan rates were higher in younger patients compared with older patients, and older stroke patients who did not have a CT scan had a significantly increased 
mortality rate. ${ }^{13}$ Whilst previous such studies have focused on the rates rather than timing of CT in the management of stroke, our study has examined the rates through different time frames in the context of potential cofounders. We found that people who had early CT scans had higher mortality even controlling for age. This could be because those who had CT scans had more severe strokes, regardless of age.

Our study has several strengths. This study has a large sample size of just under eight thousand patients and includes eight diverse NHS trusts allowing us to capture variation in the case-mix and the outcomes between different stroke services and hence the generalizability in the UK NHS setting. All stroke cases were ascertained based on clinical diagnosis and neuroimaging. The sample consists of wide ranging age bands, prestroke disability and function depicted by broad spectrum of prestroke mRS and residence status, medical factors that contribute to acute mortality outcomes such as blood pressure, ${ }^{14,15}$ atrial fibrillation ${ }^{16,17}$ and treatment with intravenous tPA. ${ }^{18,19}$

Our study also has limitations. The main limitation was that we had fair amount of missing data for pre-stroke mRS and data on atrial fibrillation. However, the internal relationship between time to $\mathrm{CT}$ and stroke outcome is unlikely to be affected by the missing data. If any, truncation of the sample distribution will only reduce the sample size and this is likely to attenuate the associations observed. Aside from atrial fibrillation, the routine AS\&HCN data did not capture the other co-morbidities and this might have influenced the time of CT scan and the subsequent management. Nevertheless, we adjusted for pre-stroke mRS which likely to reflect co-morbidities and their impact on physical ability. Some patients with stroke might not have been captured by our study e.g. those which are patients with mild stroke (not admitted to hospital or detected at TIA clinic) and very severe stroke (died before admission or decision was made not to admit to hospital i.e. palliation only). Nevertheless, this is not the remit of the study and stroke admitted to health care facilities are 
undoubtedly important. We also did not have data on National Institute of Health Stroke Scale (NIHSS) for majority and hence we were unable to control the NIHSS, which may have been useful. Nevertheless, we used OCSP classification which has prognostic significance and closely linked to NIHSS..$^{20,21}$

In summary, there are age-related differences in stroke management with regard to CT scan times. The decision to perform CT urgently appears to be dependent on patient's age, stroke severity, pre-stroke disability and residence status and thus overall perceived need of urgent CT by the clinical team. Furthermore, there is no evidence that early CT scan is associated with lower mortality outcomes. However, excess mortality rate associated with older age may be at least partially accounted for by relative delay in CT scanning compared to their younger counterparts. We conclude CT scan time as a benchmarking tool in stroke may have inherent limitations and may not be suitable as a quality marker. This study provides new insight that any benchmarking tools proposed to evaluate stroke services should not be based on factors/variables that can be influenced by clinician's decision making process on need base. 


\section{Disclosures: None}

\section{Funding}

The Anglia Stroke Clinical Network Evaluation Study (ASCNES) is funded by the National Institute for Health Research (NIHR) Research for Patient Benefit Programme (PB-PG-120818240). This paper presents independent research funded by the NIHR under its Research for Patient Benefit (RfPB) programme (Grant Reference Number PB-PG-1208-18240). The views expressed are those of the author(s) and not necessarily those of the NHS, the NIHR or the Department of Health. The Anglia Stroke and Heart Clinical Network (AS\&HCN) is funded by the National Health Service Improvement Program.

\section{Acknowledgements}

We gratefully acknowledge the funder of this research, NIHR Research for Patient Benefit Programme. We are also indebted to all the research and clinical teams based at the participating NHS Trusts, and the staff from the respective Research \& Development Departments. We also would like to thank the Anglia Stroke \& Heart Clinical Network for their support.

\section{Contributors}

PKM is the PI of the ASCNES and conceptualize the study. CSK performed the data analysis. SDM was responsible for data management. JFP, MOB, GMP, AKM, and EAW are co-applicants of the ASCNES. DJD, AKM, AN, PA, KW, RS and JN are site PIs of the eight collaborating NHS Trust. ACK, CSK and PKM wrote the first draft of the manuscript and all of the authors contributed to the manuscript and approved the final manuscript. 


\section{References}

1. Hacke W, Kaste M, Bluhmki E, et al. Thrombolysis with alteplase 3 to 4.5 hours after acute ischemic stroke. N Engl J Med 2008;359:1317-1329.

2. Rha JH, Saver JL. The impact of recanalization on ischemic stroke outcome: a metaanalysis. Stroke 2007;38:967-973.

3. Luker JA, Wall K, Bernhardt J, et al. Patients' age as a determinant of care received following acute stroke: A systematic review. BMC Health Serv Res 2011;11:161.

4. Young J. Ageism in services for transient ischemic attack and stroke. Br Med J 2006;333: 508.

5. Myint PK, Vowler SL, Redmayne O, et al. Utilisation of diagnostic computerised tomography imaging and immediate clinical outcomes in older people with stroke before and after introduction of the National Service Framework for older people. A comparative study of hospital-based stroke registry data (1997-2003): Norfolk experience. Age Ageing 2006;35:399-403.

6. Myint PK, Potter JF, Price G, et al. Evaluation of stroke services in Anglia Stroke Clinical Network to examine the variation in acute services and stroke outcomes. BMC Health Serv Res 2011;11:50.

7. Intercollegiate Stroke Working Party. National clinical guideline for stroke, Fourth edition. London: Royal College of Physicians. URL: https://www.rcplondon.ac.uk/guidelinespolicy/stroke-guidelines. Access date 29 January 2016.

8. Bamford J, Sandercock P, Dennis M, et al. Classification and natural history of clinically identifiable subtypes of cerebral infarction. Lancet 1991; 337:1521-6.

9. Di Carlo A, Lamassa M, Pracucci G, et al. Stroke in the very old: clinical presentation and determinants of 3- month functional outcome: A European perspective. Stroke 1999;30:23139. 
10. Heidrich J, Heuschmann PU, Kolominsky-Rabas P, et al. Variations in the use of diagnostic procedures after acute stroke in Europe: results from the BIOMED II study of stroke care. Eur J Neurol 2007;14:255-261.

11. McKevitt C, Coshall C, Tilling K, et al. Are there inequalities in the provision of stroke care? Analysis of an inner-city stroke register. Stroke 2005,36:315-320.

12. McKevitt C, Coshall C, Tilling K, et al. Are There Inequalities in the Provision of Stroke Care? Analysis of an Inner-City Stroke Register. Stroke 2005;36:315-320.

13. Bhalla A, Grieve R, Tilling K, et al. Older stroke patients in Europe: stroke care and determinants of outcome. Age Ageing 2004;33:618-24.

14. Prospective Studies Collaboration. Age-specific relevance of usual blood pressure to vascular mortality: a meta-analysis of individual data for one million adults in 61 prospective studies. Lancet 2002;360:1903-13.

15. Collins R, Peto R, MacMahon S, et al. Blood pressure, stroke, and coronary heart disease: Part 2, short-term reductions in blood pressure: overview of randomised drug trials in their epidemiological context. Lancet 1990;335:827-838.

16. Wyse DG, Waldo AL, DiMarco JP, et al. A comparison of rate control and rhythm control in patients with atrial fibrillation. N Engl J Med 2002;347:1825-1833.

17. Benjamin EJ, Wolf PA, D'Agostino RB, et al. Impact of Atrial Fibrillation on the Risk of Death: The Framingham Heart Study. Circulation 1998; 98:946-952.

18. Davis SM, Donnan GA. 4.5 hours: the new time window for tissue plasminogen activator in stroke. Stroke 2009;40:2266-7.

19. Wardlaw JM, Murray V, Berge E, et al. Recombinant tissue plasminogen activator for acute ischemic stroke: an updated systematic review and meta-analysis. Lancet 2012;379:2364-72. 
20. Rudd AG, Hoffman A, Down C, et al. Access to stroke care in England, Wales and Northern Ireland: the effect of age, gender and weekend admission. Age Ageing 2007;36:247-5.

21. Saposnik G, Black S, Hakim A, et al. Age disparities in stroke quality of care and delivery of health services. Stroke 2009;40:3328-3335. 


\section{Legends}

Figure 1: 3D plot of adjusted odds ratio of age (4 groups) vs. time to CT (4 groups) for in-patient mortality (Figure 1A) and seven-day mortality (Figure 1B)

Table 1: Sample characteristics and study outcomes according to time to CT from admission in Anglia Stroke \& Heart Clinical Network

Table 2: Odds ratio for inpatient and 7-day mortality according to age categories and time to CT categories in Anglia Stroke \& Heart Clinical Network 
Figure 1: 3D plot of adjusted odds ratio of age (4 groups) vs. time to CT (4 groups) for in-patient mortality (Figure 1A) and seven-day mortality (Figure 1B)

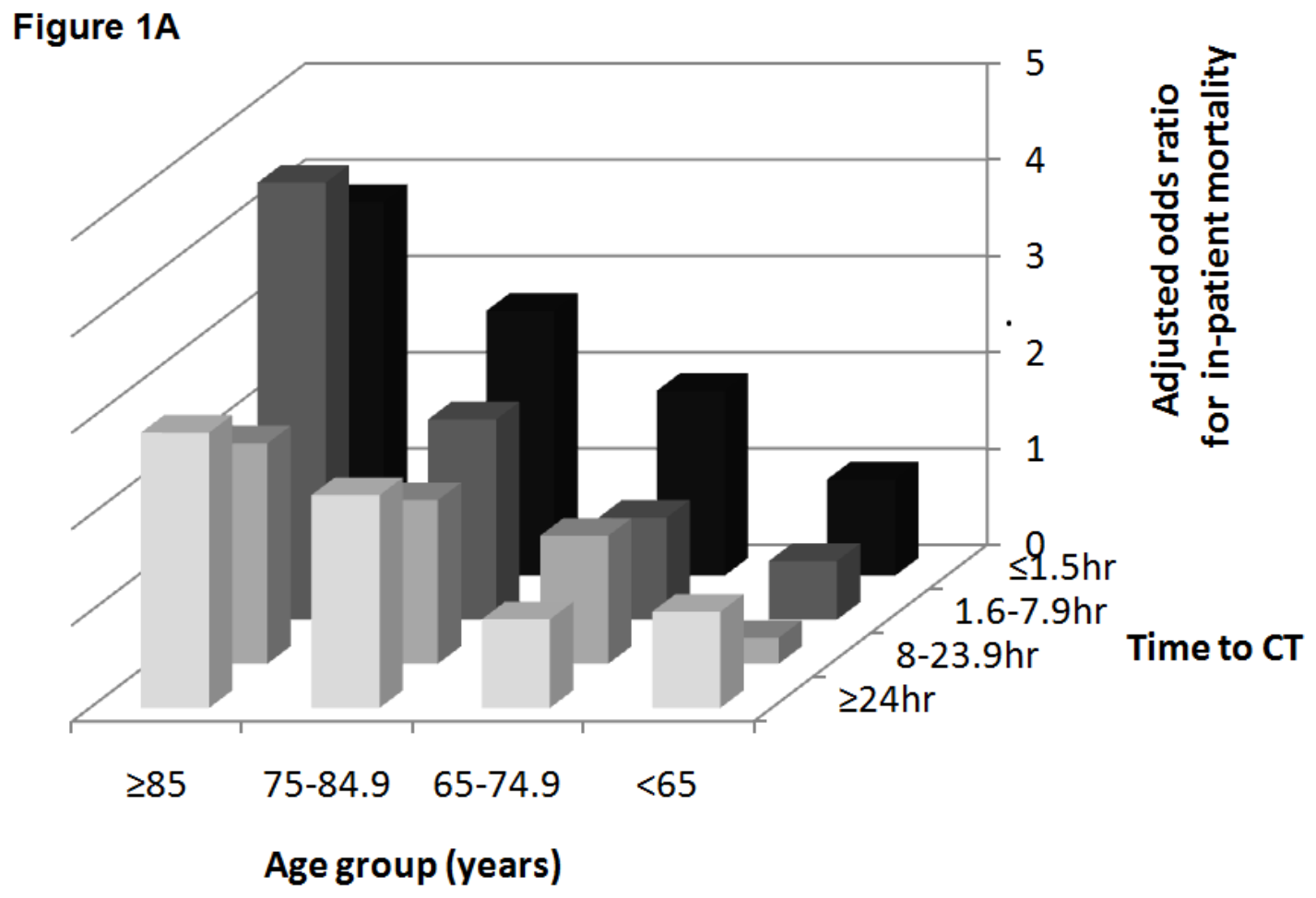

Figure 1B

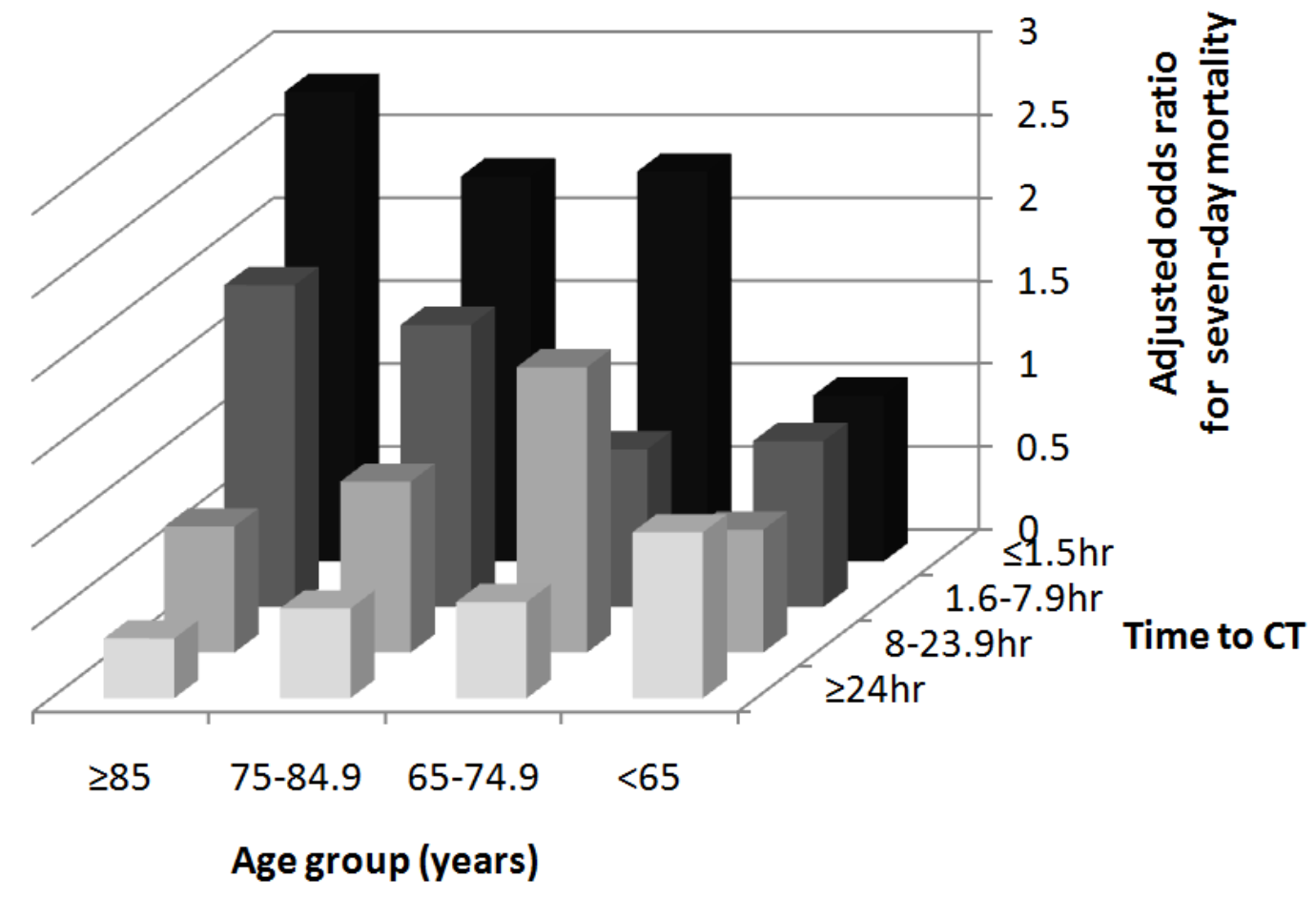


Table 1: Sample characteristics and study outcomes according to time to CT from admission in Anglia Stroke \& Heart Clinical Network

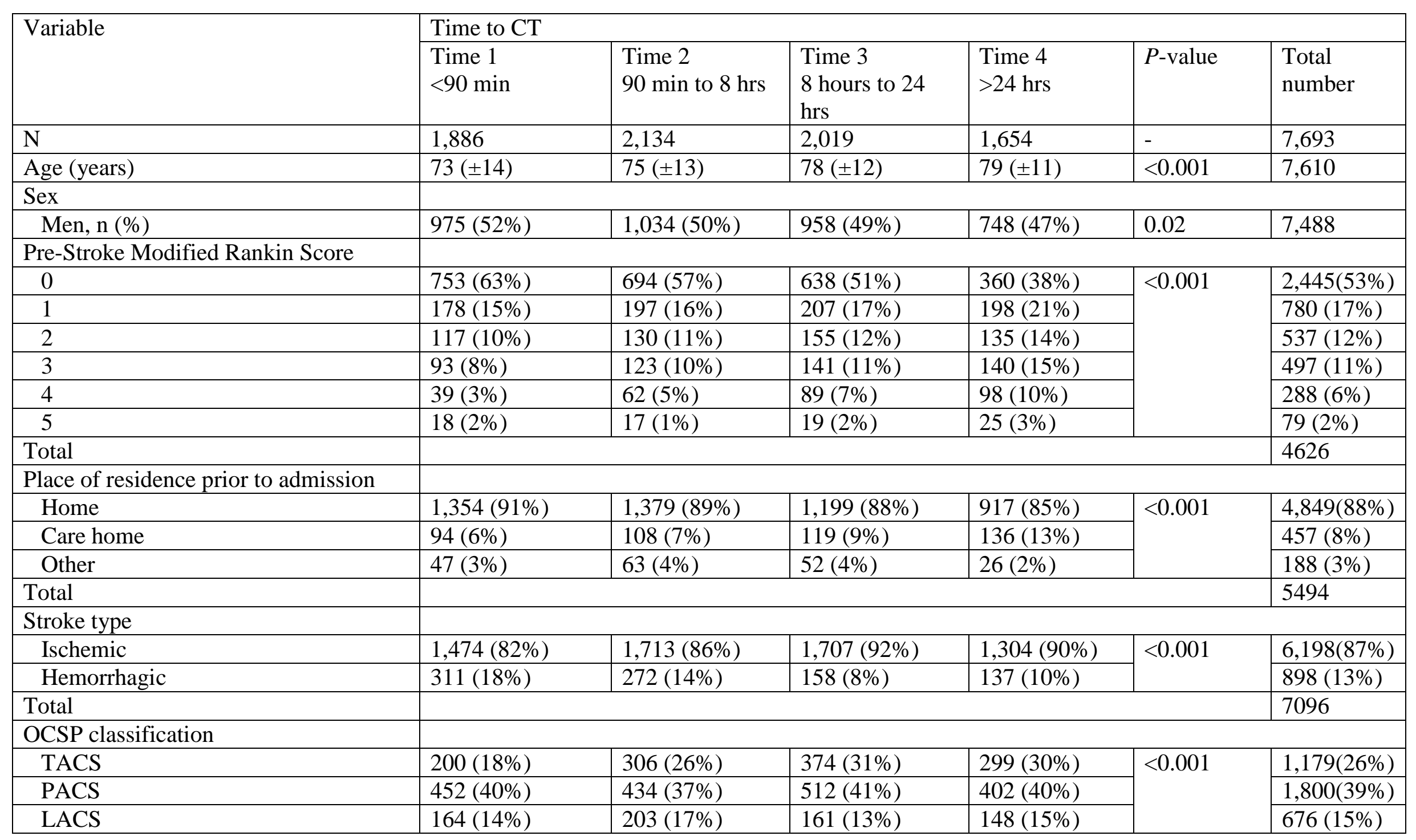




\begin{tabular}{|c|c|c|c|c|c|c|}
\hline POCS & $326(29 \%)$ & $237(20 \%)$ & $196(16 \%)$ & $157(16 \%)$ & & $916(20 \%)$ \\
\hline Total & & & & & & 4571 \\
\hline Systolic BP & $162(32 \%)$ & $159(31 \%)$ & $158(29 \%)$ & $156(28 \%)$ & $<0.001$ & 6,605 \\
\hline Thrombolysis & $262(15 \%)$ & $19(1 \%)$ & $2(0.1 \%)$ & $6(0.4 \%)$ & $<0.001$ & $289(45 \%)$ \\
\hline $\mathrm{AF}$ & $317(28 \%)$ & $323(31 \%)$ & $209(26 \%)$ & $179(31 \%)$ & 0.03 & $1,028(295)$ \\
\hline Admitted to stroke unit & $504(80 \%)$ & $708(75 \%)$ & $808(75 \%)$ & $682(70 \%)$ & $<0.001$ & $2,702(74 \%)$ \\
\hline In-patient mortality & $391(21 \%)$ & $327(15 \%)$ & $218(11 \%)$ & $215(13 \%)$ & $<0.001$ & $1,151(15 \%)$ \\
\hline In-patient mortality within 7-days & $178(9 \%)$ & $91(4 \%)$ & $42(2 \%)$ & $25(2 \%)$ & $<0.001$ & $336(4 \%)$ \\
\hline
\end{tabular}

The numbers presented are mean (SD), and number (\%).

Abbreviations: $\mathrm{CT}=$ computed tomography, $\mathrm{OSCP}=\mathrm{Oxfordshire}$ Community Stroke Project, $\mathrm{TACS}=$ total anterior circulation stroke, $\mathrm{PACS}=$ partial anterior circulation stroke, $\mathrm{LACS}=$ lacunar stroke, $\mathrm{POCS}=$ posterior circulation stroke. 
Table 2: Odds ratio for inpatient and 7-day mortality according to age categories and time to CT categories in Anglia Stroke \& Heart Clinical Network

\begin{tabular}{|c|c|c|c|c|c|c|c|c|}
\hline & \multicolumn{4}{|c|}{ In-patient mortality } & \multicolumn{4}{|c|}{ 7-day mortality } \\
\hline & $\begin{array}{l}\text { No. death/ } \\
\text { No. total }\end{array}$ & $\begin{array}{l}\text { Unadjusted } \\
\text { odds ratio } \\
(95 \% \mathrm{CI})^{\#}\end{array}$ & $\begin{array}{l}\text { Adjusted } \\
\text { odds ratio } \\
\text { model } 1 \\
(95 \% \mathrm{CI})^{* \dagger}\end{array}$ & $\begin{array}{l}\text { Adjusted odds } \\
\text { ratio model } 2 \\
(95 \% \mathrm{CI})^{*}+\end{array}$ & $\begin{array}{l}\text { No. death/ } \\
\text { No.total }\end{array}$ & $\begin{array}{l}\text { Unadjusted } \\
\text { odds ratio } \\
(95 \% \text { CI })^{\#}\end{array}$ & $\begin{array}{l}\text { Adjusted odds } \\
\text { ratio model } 1 \\
(95 \% \mathrm{CI})^{* \dagger}\end{array}$ & $\begin{array}{l}\text { Adjusted odds } \\
\text { ratio model } 2 \\
(95 \% \mathrm{CI})^{*}+\end{array}$ \\
\hline Age cat 1 & $66 / 1,331$ & 1.00 & 1.00 & 1.00 & $26 / 1,331$ & 1.00 & 1.00 & 1.00 \\
\hline Age cat 2 & $141 / 1,483$ & $\begin{array}{l}2.01 \\
(1.49-2.72)\end{array}$ & $\begin{array}{l}2.17 \\
(1.60-2.94)\end{array}$ & $\begin{array}{l}1.92 \\
(1.14-3.23)\end{array}$ & $52 / 1,483$ & $\begin{array}{l}1.82 \\
(1.13-2.94)\end{array}$ & $\begin{array}{l}2.10 \\
(1.30-3.40)\end{array}$ & $\begin{array}{l}2.90 \\
(1.24-6.80)\end{array}$ \\
\hline Age cat 3 & $412 / 2,607$ & $\begin{array}{l}3.60 \\
(2.75-4.71)\end{array}$ & $\begin{array}{l}4.11 \\
(3.13-5.39)\end{array}$ & $\begin{array}{l}3.15 \\
(1.98-5.01)\end{array}$ & $136 / 2,607$ & $\begin{array}{l}2.76 \\
(1.81-4.22)\end{array}$ & $\begin{array}{l}3.56 \\
(2.32-5.47)\end{array}$ & $\begin{array}{l}3.03 \\
(1.37-6.70)\end{array}$ \\
\hline Age cat 4 & $519 / 2,189$ & $\begin{array}{l}5.96 \\
(4.56-7.77)\end{array}$ & $\begin{array}{l}7.34 \\
(5.60-9.62)\end{array}$ & $\begin{array}{l}4.78 \\
(2.99-7.65)\end{array}$ & $119 / 2,189$ & $\begin{array}{l}2.98 \\
(1.93-4.58)\end{array}$ & $\begin{array}{l}4.36 \\
(2.82-6.74)\end{array}$ & $\begin{array}{l}3.14 \\
(1.39-7.09)\end{array}$ \\
\hline Time to CT 1 & $391 / 1,886$ & 1.00 & 1.00 & 1.00 & $178 / 1,886$ & 1.00 & 1.00 & 1.00 \\
\hline Time to CT 2 & $327 / 2,134$ & $\begin{array}{l}0.69 \\
(0.59-0.81)\end{array}$ & $\begin{array}{l}0.59 \\
(0.50-0.70)\end{array}$ & $\begin{array}{l}0.86 \\
(0.64-1.15)\end{array}$ & $91 / 2,134$ & $\begin{array}{l}0.43 \\
(0.33-0.55)\end{array}$ & $\begin{array}{l}0.39 \\
(0.30-0.50)\end{array}$ & $\begin{array}{l}0.61 \\
(0.39-0.95)\end{array}$ \\
\hline Time to CT 3 & $218 / 2,019$ & $\begin{array}{l}0.46 \\
(0.39-0.55)\end{array}$ & $\begin{array}{l}0.36 \\
(0.30-0.43)\end{array}$ & $\begin{array}{l}0.57 \\
(0.42-0.78)\end{array}$ & $42 / 2,019$ & $\begin{array}{l}0.20 \\
(0.14-0.29)\end{array}$ & $\begin{array}{l}0.17 \\
(0.12-0.25)\end{array}$ & $\begin{array}{l}0.39 \\
(0.24-0.64)\end{array}$ \\
\hline Time to CT 4 & $215 / 1,654$ & $\begin{array}{l}0.57 \\
(0.48-0.68)\end{array}$ & $\begin{array}{l}0.41 \\
(0.34-0.49)\end{array}$ & $\begin{array}{l}0.71 \\
(0.52-0.98)\end{array}$ & $25 / 1,654$ & $\begin{array}{l}0.15 \\
(0.10-0.23)\end{array}$ & $\begin{array}{l}0.11 \\
(0.07-0.18)\end{array}$ & $\begin{array}{l}0.16 \\
(0.08-0.33)\end{array}$ \\
\hline
\end{tabular}

Logistic regression model unadjusted, adjusted model 1 (age and time to CT only) *adjusted model 2 (age, time to CT, sex, pre-stroke modified Rankin, stroke type and OCSP classification in model)

Age cat $1=<65$, age cat $2=\geq 65 \&<75$, age cat $3=\geq 75 \&<85$, age cat $4=\geq 85$

Time to CT $1=<90 \mathrm{~min}$, Time to CT $2=\geq 90 \mathrm{~min} \&<8$ hours, Time to CT $3=\geq 8$ hours $\&<24$ hours, Time to CT $4=\geq 24$ hours

${ }_{\mathrm{n}} \mathrm{n}=7,693$

$\dagger \mathrm{n}=7,610$

$\ddagger \mathrm{n}=3,481$ 
Supplementary Figure 1: Flow diagram of reason for exclusion

\begin{tabular}{|l|l|}
\hline $\begin{array}{l}\text { Original data set } 8,756 \text { patients in } \\
\text { AS\&HCN data. }\end{array}$ & $\longrightarrow \begin{array}{l}1,063 \text { participants were excluded } \\
\text { because patient had diagnosis of } \\
\text { TIA }(\mathrm{n}=28), \text { missing time to } \mathrm{CT} \\
\text { scan }(\mathrm{n}=1,035) .\end{array}$ \\
\cline { 2 - 3 } & \\
\hline 7,693 participants included in
\end{tabular}

analysis. 